\title{
Overweight trajectory and cardio metabolic risk factors in young adults
}

\author{
Gabriela Callo Quinte ${ }^{1 *}$ (D), Fernando Barros ${ }^{1,2}$, Denise Petrucci Gigante ${ }^{1}$, Isabel Oliveira de Oliveira', \\ Janaína Vieira dos Santos Motta ${ }^{1}$ and Bernardo Lessa Horta ${ }^{1}$
}

\begin{abstract}
Background: Obesity is one of the conditions that increases the risk of cardiovascular disease. Studies about obesity trajectory and cardio metabolic outcomes at adulthood are still scarce. Therefore, we aimed to assess the association between patterns of overweight over the life-course and cardio metabolic risk factors in young adults.

Methods: In 1982, the maternity hospitals in Pelotas were visited daily and those newborns whose family lived in the urban area of the city were identified $(n=5914)$, and have prospectively followed for several occasions. Weight and height were measured at every visit. BMI-for-age z-score was calculated using the WHO Child Growth Standards. Overweight and obesity were defined as a BMl greater than or equal to $25 \mathrm{~kg} / \mathrm{m} 2$ and $30 \mathrm{~kg} / \mathrm{m} 2$ respectively. This was the definition adopted for evaluations overweight and obesity at 30 years. The participants were divided into eight groups according to the presence of overweight or obesity in childhood, adolescence and adulthood. Blood pressure, random blood glucose, HDL cholesterol, LDL cholesterol triglycerides and fat mass were measured.

Results: From 2219 participants with anthropometric data in childhood, adolescence and adulthood, 25\% never had been overweight, whereas $11.6 \%$ were overweight in the three periods. Random blood glucose, SBP and DBP were higher among those subjects who were always overweight/ obese or only overweight/obese during adolescence and adulthood. The participants who were never overweight/obese or only in childhood or adolescence had a lower cardiovascular risk profile (higher HDL cholesterol, lower blood pressure, lower random glucose, lower LDL cholesterol) at 30 years. Fat mass captured from 25 to 100\% of the association of overweight and obesity trajectory with cardiometabolic risk factors.
\end{abstract}

Conclusions: The tracking of overweight/obesity is associated with an adverse cardio metabolic profile and this association is largely mediated by fat mass in adulthood.

Keywords: Obesity, Trajectory, Cardiometabolic risk factors, Young adults

\section{Background}

Cardiovascular diseases (CVD) remain the major cause of heath loss and accounting for 17.5 million deaths (31\% of all deaths) worldwide [1,2]. One of the conditions that increases the risk of cardiovascular death is obesity [3]. Obese subjects are almost twice as likely to develop CVD [4]. It has been estimated that 35.8 million (2.3\%) of Disability Adjusted Life Years (DALYs) around the world are due to overweight or obesity and every year at least 2.8 million people die as a result of being

\footnotetext{
* Correspondence: gavizon7@hotmail.com

${ }^{1}$ Postgraduate Program in Epidemiology, Federal University of Pelotas, Caixa postal 354, Marechal Deodoro, 1160, Pelotas, RS 96020-220, Brazil

Full list of author information is available at the end of the article
}

overweight or obese [5]. Because the prevalence of obesity has increased, its contribution to the burden of disease must also have risen [6].

There is evidence that childhood obesity is considered as a cardio metabolic risk predictor in adulthood [7]. The association between obesity and cardiovascular disease would be mainly mediated by increased level of metabolic cardiovascular risk factors [8], since obesity is associated with higher blood pressure [9], Low Density Lipoprotein (LDL) cholesterol, triglycerides, blood glucose and lower High Density lipoprotein (HDL) cholesterol [7, 8, 10-13].

A systematic review has shown that excessive weight gain during the life course increases the risk of hypertension [14]. Another review showed that the tracking of

(c) The Author(s). 2019 Open Access This article is distributed under the terms of the Creative Commons Attribution 4.0 International License (http://creativecommons.org/licenses/by/4.0/), which permits unrestricted use, distribution, and reproduction in any medium, provided you give appropriate credit to the original author(s) and the source, provide a link to the Creative Commons license, and indicate if changes were made. The Creative Commons Public Domain Dedication waiver (http://creativecommons.org/publicdomain/zero/1.0/) applies to the data made available in this article, unless otherwise stated. 
childhood weight into adulthood is moderated for overweight and obese youth [15]. Most of these studies considered only two time points and were conducted in high-income countries.

Because of literature about obesity trajectory and cardio metabolic outcomes at adulthood is still scarce, this study aimed at assessing the association between patterns of overweight over the life-course and cardio metabolic risk factors (random glucose, blood pressure, LDL cholesterol, HDL cholesterol and triglycerides) at 30 years of age.

\section{Methods}

In 1982, we identified all hospital births in Pelotas, a Southern Brazilian city. The liveborns whose families lived in the urban area were examined and their mothers interviewed $(n=5914)$. These individuals were followed up on various occasions. In childhood ( $2 / 4 \mathrm{yrs})$, the subjects were weighed and measured using portable scales and stadiometers by trained staff [16]. During adolescence, in 2000, male subjects were identified while they were participating in the mandatory military recruitment (18 yrs) and were interviewed during the military medical examination. In 2001, a systematic sample of 70 census tracts was selected and a census was carried out in these tracts in search of cohort members, who were interviewed and examined [17]. In 2012-13 (mean age of 30.2 years), the cohort members were contacted and invited to visit the research clinic for interview, examination, and donation of a blood sample [18]. Weight was measured using the Bod $\mathrm{POD}^{\circ}$ scale and height with a portable stadiometer (aluminum and wood) with accuracy of $100 \mathrm{~g}$ and $0.1 \mathrm{~cm}$, respectively.

Body mass index (BMI) was estimated from weight and height measurements. Overweight and obesity in childhood ( 2 and/or 4 years) and adolescence (19 and 20 years), were defined according to specific cutoff points for sex and age (BMI/age), as proposed by World Health Organization (WHO) [19]. Overweight and obesity were defined as a BMI greater than or equal to $25 \mathrm{~kg} / \mathrm{m} 2$ and $30 \mathrm{~kg} / \mathrm{m} 2$ respectively $[2,20]$. This was the definition adopted for evaluations overweight and obesity at 30 years. Based on these definitions, the participants were categorized into eight groups according to the presence of overweight or obesity in childhood, adolescence and adulthood. i.e.: never obese, childhood only, adolescence only, adulthood only, childhood and adolescence, childhood and adulthood, adolescence and adulthood and always. For the analysis, we collapsed the eight groups into six putting together childhood only, adolescent only and childhood and adolescent only. Thus, the new six groups were: never, childhood/adolescence only, adulthood only, childhood and adulthood, adolescence and adulthood and always.
In the present manuscript, we evaluated the association of the overweight/obesity trajectory with the following metabolic cardiovascular risk factors at age 30 years:

- Blood pressure was measured using a wrist digital sphygmomanometer (Omron HEM-742) at the beginning and at the end of the interview with the participant seated and the arm supported at chest level, and the mean of the two measurements was used in the present analyses.

- Random blood glucose was measured using an automatic enzymatic colorimetric method in chemistry analyzer BS-380, Mindray (Shenzhen Mindray BioMedical Electronics Co., Ltd., China). Because glucose levels vary according to fasting time, estimates were adjusted for time since last meal using linear regression models with glucose as the dependent variable, and time since the last meal as independent variable.

- HDL cholesterol, LDL cholesterol and triglycerides were measured enzymatically (Shenzhen Mindray Bio-Medical Electronics Co., Ltd., China).

Fat mass was estimated by air displacement plethysmography (BOD POD), using the Siri equation [21].

The following variables were considered as confounders: family income at birth (in minimum wages), maternal schooling at birth (in completed years), maternal smoking during pregnancy (yes/no), skin color, sex, physical activity at 30 years, assessed using the International Physical Activity Questionnaire (IPAQ) [22] large version, income at 30 years and fasting time (used for random glucose, HDL cholesterol, ldl cholesterol and triglycerides). In the crude analysis, analysis of variance was used to compare the means. In the multivariate analysis, we used multiple linear regression to obtain estimates that were adjusted for confounding. We used G computation to assess the mediating effect of fat mass at 30 years in the association between overweight trajectory and cardio metabolic risk factors and estimated the natural direct effect (NDE) and natural indirect effects (NIE). The NDE represents the effect that goes directly to the outcome from the exposure without passing through the mediator (fat mass). The NIE is the effect that passes through the mediator (fat mass) [23]. In the G-computation analysis, base confounders included the variables considered as confounders in the linear regression. Physical activity at 30 years and current income were included as post confounders (Additional file 1: Figure S1), i.e., variables that could also confound the relationship between the mediator (fat mass) and the outcomes (cardio metabolic risk factors).

Study protocols were approved by the Ethics Committee of the Federal University of Pelotas. Verbal consent was obtained from those responsible for the children in the 
initial phases of the study (1982-1986). All participants signed an informed consent form before any interviews and evaluations.

\section{Results}

In 2012-13, 3701 subjects were interviewed, which added to the 325 known to have died, represented a follow-up rate of $68.1 \%$. In the present study, we analyzed 2219 subjects who had weight and height measurement in childhood, adolescence and adulthood (Fig. 1).

About one of every four subjects were never overweight, whereas $11.6 \%$ were overweight in the three periods. Table 1 shows the socio-demographic characteristics of study participants, most of them were white
(75.5\%), their mothers had completed 5 to 8 school years (43.1\%) and $6.2 \%$ were low birth weight.

Table 1 The association of these variables with the exposure and outcomes is provided in Additional file 2: Table S1, Additional file 3: Table S2.

Tables 2 and 3 show that systolic and diastolic blood pressure were higher among those subjects who were always overweight/obese or during adolescence and adulthood. On the other hand, those who were overweight/obese only in childhood or adolescence had similar crude mean values to those who were never considered as overweight. For random blood glucose, we observed a similar pattern of association. These associations were observed even after controlling for possible confounding variables.

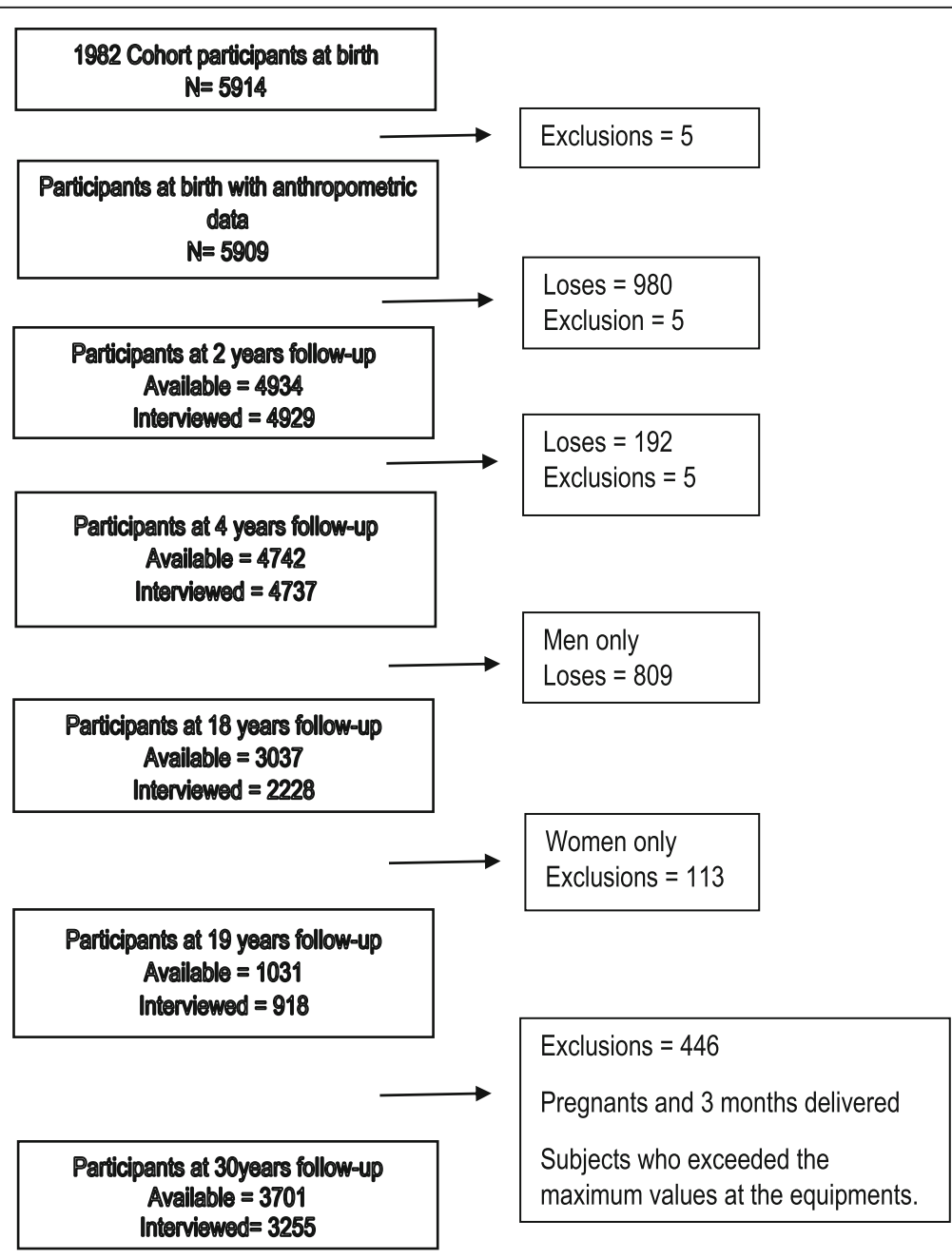

Total participants in the study* $\mathrm{N} \equiv \mathbf{2 8 5 3}$

Fig. 1 Flow chart of the Pelotas 82 cohort Participants. *All the subjects that had height and weight measurement during childhood, adolescence and adulthood 
Table 1 Characteristics of Pelotas Cohort participants who had weight and height data in childhood, adolescence and adulthood

\begin{tabular}{|c|c|c|c|c|c|}
\hline Variable & $\mathrm{N}$ & $\%$ or Mean (SD) & Variable & $\mathrm{N}$ & $\%$ or Mean (SD) \\
\hline Sex & & & Never & 762 & $(26.7)$ \\
\hline Male & 2002 & $(70,2)$ & Chilhood or adolescence only & 544 & $(19.1)$ \\
\hline Female & 851 & $(8,29)$ & Adulthood only & 553 & $(19.4)$ \\
\hline Ethnicity & & & Childhood + adulthood & 530 & $(18.5)$ \\
\hline White & 1721 & $(75,5)$ & Adolescence + adulthood & 134 & $(4.7)$ \\
\hline Black/brown & 486 & $(3,21)$ & Always & 330 & $(11.6)$ \\
\hline Others & 74 & $(2,3)$ & Total & 2853 & \\
\hline
\end{tabular}

Family income at birth (tertile)

Mother schooling at birth (years)

$0-4$

9-11

12 or more

Birth weight (g)

$$
<2500
$$

2500 a 3499

$\geq 3500$

Gestational age (weeks)

$$
<37
$$

$37-41$

$\geq 42$ )

Childhood

Overweight

Obesity

Adolescence

Overweight

Obesity

Adulthood

Overweight
Obese

Cardio metabolic risk factors at 30 years

$$
\begin{aligned}
& \text { Systolic blood pressure }(\mathrm{mmHg}) \\
& \text { Diastolic blood pressure }(\mathrm{mmHg}) \\
& \text { Random glucose }(\mathrm{mg} / \mathrm{dl}) \\
& \mathrm{HDL} \text { cholesterol }(\mathrm{mg} / \mathrm{dl}) \\
& \mathrm{LDL} \text { cholesterol }(\mathrm{mg} / \mathrm{dl}) \\
& \text { Triglycerides }(\mathrm{mg} / \mathrm{dl}) \\
& \text { Fat mass }(\%) \\
& \text { Overweight patterns }
\end{aligned}
$$

Table 1 Characteristics of Pelotas Cohort participants who had weight and height data in childhood, adolescence and adulthood (Continued)

Concerning triglycerides, HDL and LDL cholesterol, the participants who were never overweight/obese or only in childhood or adolescence had a lower cardiovascular risk profile (higher HDL, lower LDL and triglycerides), whereas those who were overweight/obese at adulthood (independent of episodes of overweight/obesity at any other period) had the lowest levels of HDL and highest LDL and triglycerides. The direction of the associations was similar for men and women (data not shown). However, we found that after controlling adult $\mathrm{BMI}$, the trajectory association decreased (Additional file 4: Table S3).

In the mediation analysis, we observed that fat mass captured from 25 to $100 \%$ of the effect of overweight and obesity trajectory on the cardio metabolic risk factors (Additional file 5:Table S4, Additional file 6:Table S5).

\section{Discussion}

In a population that has been prospectively followed since birth, we observed that overweight throughout life course or during adolescence and adulthood was associated with higher systolic and diastolic blood pressure, random glucose, and lower HDL cholesterol, whereas being overweight only in adulthood showed an intermediate effect. On the other hand, LDL cholesterol and triglycerides were associated with current body mass index, independent of what had been observed at earlier ages. After controlling adult BMI, the trajectory association decreased reinforcing our thesis that what matters is the current BMI. In addition, we observed that a great part of these associations was explained by fat mass in adulthood.

We found that individuals exposed to overweight in childhood and/or adolescence and become non obese in adulthood showed similar cardio metabolic profile to those who had never presented overweight. These findings are in agreement with Juonala et al., who observed that a decrease in adiposity from childhood to adulthood was associated with a marked reduction in the risk of hypertension, type 2 diabetes, and dyslipidemia [10]. Furthermore, a pooled analysis from three British birth 


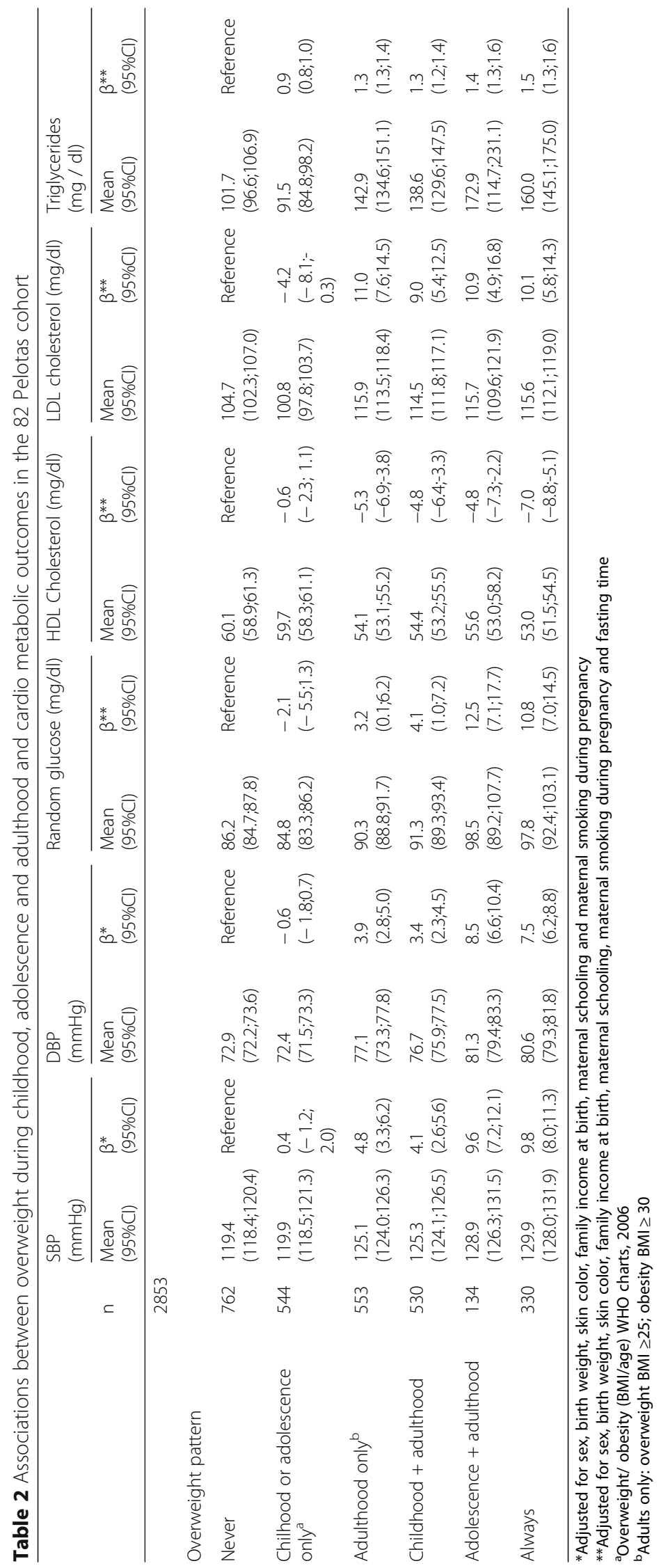




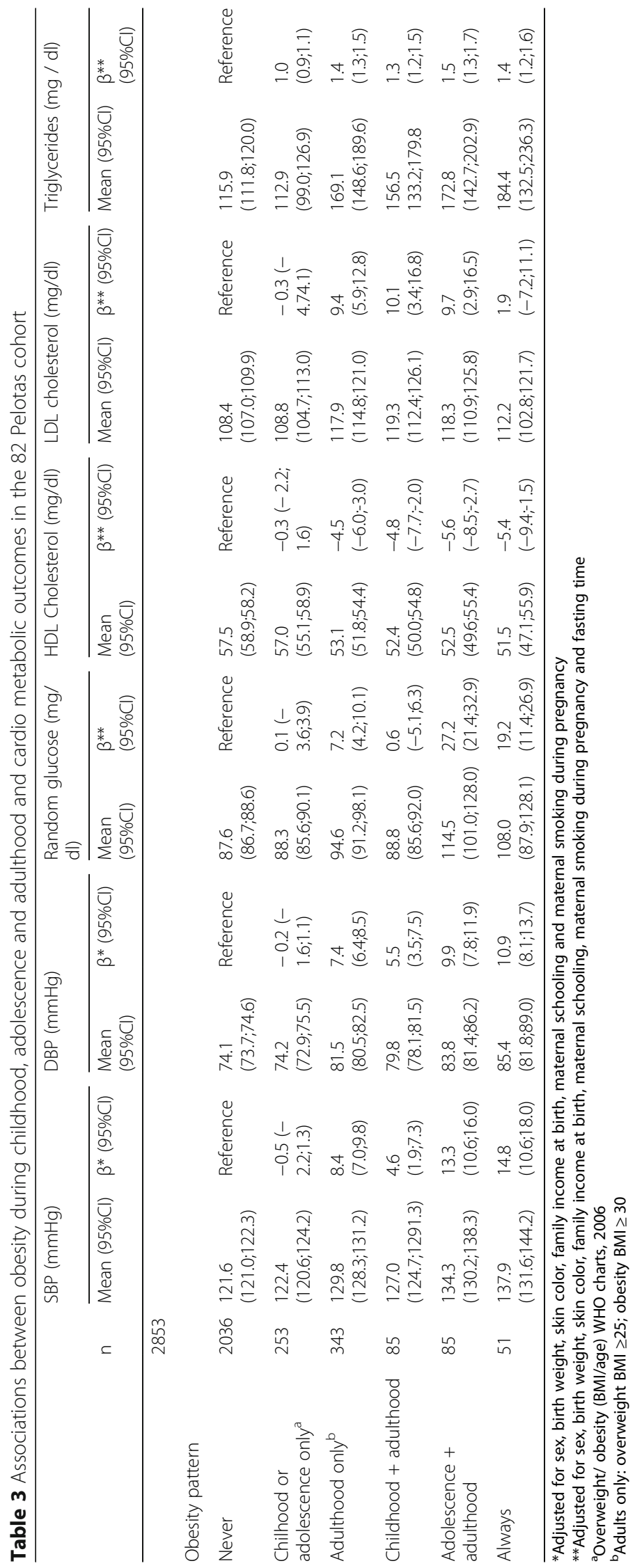


cohorts reported an increased risk of type 2 diabetes, when overweight presented at different stages of life (childhood, adolescence and adulthood), but overweight in childhood was not associated with higher risk for subjects who were not overweight in adulthood [24]. In addition, a recent study using observational data suggest that stabilizing BMI among obese adults could help limit their adverse CVD risk profiles and that reversing high BMI in young adulthood may lead to better cardio metabolic profiles than remaining stable overweight [25].

A previous study from this same cohort showed that a continuous exposure to overweight was associated with higher fat mass in adulthood showing a cumulative effect, whereas those who were overweight only at childhood or adolescence presented similar body composition to those who were never overweight [26]. In this study, most of the effect of overweight trajectory on the cardio metabolic risk factors was captured by fat mass. Thus, because fat mass is positively associated with cardio metabolic risk [27-29], it is not surprising that fat mass is the main mediator of the association between overweight tracking and cardio metabolic risk. Indeed, recovering normal weight at adulthood reduce fat mass and then, the cardio metabolic risk [10].

We were unable to track down $31.9 \%$ of the cohort members. However, the follow-up rate was slightly higher among those in the intermediate socioeconomic groups and reasonably similar among different subgroups (ranging from 60 to $75 \%$ in all variables studied) [18]. Therefore, it is unlikely that the observed association was due to attrition bias. Blood samples were obtained at random and only $7.2 \%$ of the subjects reported a fasting time of $12 \mathrm{~h}$ of more. On the other hand, fasting time was not associated with episodes of overweight/obesity over the life course. Therefore, it is unlikely that the observed associations were due to a differential misclassification. Indeed, we would expect a non-differential misclassification that would tend to underestimate the magnitude of the associations. In spite of BMI has some limitations [30], it is still the most used worldwide index to estimate overweight/obesity. We acknowledge the relevance of also examining the consequences of small changes in BMI. Nonetheless, we were willing to assess the effect of changing overweight/obesity status through the life cycle. Our model points out the potential benefits of early intervention to reduce overweight and minimize individuals' exposure to cardio metabolic risk factors. In terms of public health, this analysis brings a clearer message to policy makers.

\section{Conclusions}

In summary, our results indicate that the tracking of overweight/obesity is associated with an adverse cardio metabolic profile and this association is largely mediated by fat mass in adulthood. However, interruption of tracking can reverse this effect. This evidence highlights the importance of not only early intervention to reduce obesity and therefore, cardio metabolic risk factors, but also during the entire life course.

\section{Additional files}

Additional file 1: FigureS1. Direct Acyclic Graph of the association between overweight trajectory and cardio metabolic risk factors (i.e. systolic blood pressure). BC = Base confounders, which included, birth weight, mother's schooling, smoking and income at birth. PC=Post Confounders, which included, income at 30 years and physical activity at 30 years. (DOCX $20 \mathrm{~kb}$ )

Additional file 2: Table S1. Overweight pattern according to confounding variables. (DOCX $14 \mathrm{~kb}$ )

Additional file 3: Table S2. Cardio metabolic risk factors, according to confounding variables. (DOCX $15 \mathrm{~kb}$ )

Additional file 4: Table S3. Associations between overweight/obesity during childhood, adolescence and adulthood and cardiovascular outcomes in the 82 Pelotas cohort adjusted for BMl at 30 years. * Adjusted for BMl at 30 years, sex, birth weight, skin color, family income at birth, maternal schooling, maternal smoking during pregnancy. ${ }^{* *}$ Adjusted for BMl at 30 years, sex, birth weight, skin color, family income at birth, maternal schooling, maternal smoking during pregnancy and fasting time (DOCX $15 \mathrm{~kb}$ )

Additional file 5: Table S4: Mediation analysis of the association between overweight trajectory and cardio metabolic risk factors. Mediated by fat mass. *Adjusted for base confounder: low birth weight, skin color, mother schooling, sex, maternal smoking in pregnancy, and family income at birth and post confounders: physical activity at 30 years. $\mathrm{Cl}=$ Confidence Interval. (DOCX $12 \mathrm{~kb}$ )

Additional file 6: Table S5: Mediation analysis of the association between obesity trajectory and cardio metabolic risk factors. Mediated by fat mass. *Adjusted for base confounder: low birth weight, skin color, mother schooling, sex, maternal smoking in pregnancy, and family income at birth and post confounders: physical activity at 30 years. $\mathrm{Cl}=$ Confidence Interval. (DOCX $12 \mathrm{~kb})$

\section{Abbreviations}

BMI: Body Mass Index; CVD: Cardiovascular diseases; DALY's: Disability Adjusted Life Years; HDL: High Density lipoprotein; IPAQ: International Physical Activity Questionnaire; LDL: Low Density Lipoprotein; NDE: Natural direct effect; NIE: natural indirect effect; WHO: World Health Organization

\section{Acknowledgements}

This article is based on data from the study "Pelotas Birth Cohort, 1982" conducted by the Postgraduate Program in Epidemiology at Federal University of Pelotas with the collaboration of the Brazilian Public Health Association (ABRASCO).

\section{Funding}

This study was supported by the Wellcome Trust and the Brazilian Research Council (CNPq). Previous phases of the study were supported by the International Development Research Center (Canada), the World Health Organization, Overseas Development Administration, European Union, National Support Program for Centers of Excellence (PRONEX), the Brazilian National Research Council (CNPq) and Brazilian Ministry of Health. None of the sponsors participated in the design and conduct of the study; collection, management, analysis, and interpretation of the data; or preparation, review, or approval of the manuscript.

\section{Availability of data and materials}

The datasets used and analyzed during the current study are available from the corresponding author on reasonable request.

\section{Authors' contributions}

GCQ and BLH conceived and designed the study. GCQ analyzed the data. GCQ and BLH wrote the manuscript. FB, DPG, 100 and JVSM wrote and reviewed manuscript drafts. All the authors revised the manuscript for final submission and approved the final manuscript. 


\section{Ethics approval and consent to participate}

Verbal consent was obtained from those responsible for the children in the initial phases of the study (1982-1986), as was the common practice at that time, when there was no ethics committee at the Federal University of Pelotas. In the next phases, the Medical Ethics Committee of the Federal University of Pelotas approved the study protocol and all follow-ups of the Pelotas 1982 Birth Cohort Study. Participants signed a consent form on behalf of them at each follow-up, after being informed of the study objectives.

\section{Consent for publication}

Not applicable.

\section{Competing interests}

The authors declare that they have no competing interests.

\section{Publisher's Note}

Springer Nature remains neutral with regard to jurisdictional claims in published maps and institutional affiliations.

\section{Author details}

'Postgraduate Program in Epidemiology, Federal University of Pelotas, Caixa postal 354, Marechal Deodoro, 1160, Pelotas, RS 96020-220, Brazil.

${ }^{2}$ Postgraduate Program in Health and Behaviour, Catholic University of Pelotas, Pelotas, Brazil.

Received: 7 January 2018 Accepted: 28 February 2019

Published online: 11 March 2019

\section{References}

1. World Health Organization. Global status report on noncommunicable diseases 2014. World Health Organization. http://www.who.int/iris/handle/ 10665/148114

2. Roth GA, Johnson C, Abajobir A, Abd-Allah F, Abera SF, Abyu G, et al. Global, regional, and National Burden of cardiovascular diseases for 10 causes, 1990 to 2015. J Am Coll Cardiol. 2017;70(1):1-25.

3. Reilly JJ, Methven E, McDowell ZC, Hacking B, Alexander D, Stewart L, et al. Health consequences of obesity. Arch Dis Child. 2003;88(9):748-52.

4. Romero-Corral A, Montori VM, Somers VK, Korinek J, Thomas RJ, Allison TG, et al. Association of bodyweight with total mortality and with cardiovascular events in coronary artery disease: a systematic review of cohort studies. Lancet. 2006;368(9536):666-78.

5. Mendis SPP, Norrving B. Global atlas on cardiovascular disease prevention and control. Geneva: World Health Organization; 2011.

6. Ng M, Fleming T, Robinson M, Thomson B, Graetz N, Margono C, et al. Global, regional, and national prevalence of overweight and obesity in children and adults during 1980-2013: a systematic analysis for the global burden of disease study 2013. Lancet. 2014;384(9945):766-81.

7. Freedman DS, Khan LK, Dietz WH, Srinivasan SR, Berenson GS. Relationship of childhood obesity to coronary heart disease risk factors in adulthood: the Bogalusa heart study. Pediatrics. 2001;108(3):712-8.

8. Lavie CJ, Milani RV, Ventura HO. Obesity and cardiovascular disease: risk factor, paradox, and impact of weight loss. J Am Coll Cardiol. 2009; 53(21):1925-32.

9. Vaněčková I, Maletínská L, Behuliak M, Nagelová V, Zicha J, Kuneš J. Obesityrelated hypertension: possible pathophysiological mechanisms. J Endocrinol. 2014;223(3):R63-78.

10. Juonala M, Magnussen CG, Berenson GS, Venn A, Burns TL, Sabin MA, et al. Childhood adiposity, adult adiposity, and cardiovascular risk factors. N Engl J Med. 2011;365(20):1876-85.

11. Gregory CO, Martorell R, Narayan KM, Ramirez-Zea M, Stein AD. Five-year changes in adiposity and cardio-metabolic risk factors among Guatemalan young adults. Public Health Nutr. 2009;12(2):228-35.

12. Howe L, Tilling K, Benfield L, Logue J, Sattar N, Ness A, et al. Changes in ponderal index and body mass index across childhood and their associations with fat mass and cardiovascular risk factors at age 15. PLoS One. 2010;5:e15186.

13. Strandberg TE, Strandberg AY, Salomaa W, Pitkälä KH, Tilvis RS, Sirola J, et al. Explaining the obesity paradox: cardiovascular risk, weight change, and mortality during long-term follow-up in men. Eur Heart J. 2009; 30(14):1720-7.
14. Lloyd L, Langley-Evans SC, McMullen S. Childhood obesity and adult cardiovascular disease risk: a systematic review. Int J Obes. 2009;34(1):18-28,

15. Singh AS, Mulder C, Twisk JWR, Van Mechelen W, Chinapaw MJM. Tracking of childhood overweight into adulthood: a systematic review of the literature. Obes Rev. 2008;9(5):474-88.

16. Victora CG, Barros FC, Lima RC, Behague DP, Gon alves H, Horta BL, et al. The Pelotas birth cohort study, Rio Grande do Sul, Brazil, 1982-2001. Cadernos de saude publica. 2003;19(5):1241-56.

17. Barros FC, Victora CG, Horta BL, Gigante DP. Metodologia do estudo da coorte de nascimentos de 1982 a 2004-5, Pelotas, RS. Revista de saude publica. 2008:42:7-15.

18. Horta BL, Gigante DP, Gonçalves H, dos Santos Motta J, Loret de Mola C, Oliveira IO, et al. Cohort profile update: the 1982 Pelotas (Brazil) birth cohort study. Int J Epidemiol. 2015;44(2):441-e.

19. WHO. WHO Child Growth Standards: Length/height-for-age, weight-for-age, weight-for-length, weight-for-height and body mass index-for-age: methods and development. Geneva: World Health Organization; 2006.

20. WHO WECoPS. Physical status: the use and interpretation of anthropometry: report of a WHO expert commitee. Geneva: World Health Organization; 1995.

21. Siri WE. Body composition from fluid spaces and density: analysis of methods. In: Brozek JAH, editor. Techiques for measuring body composition Washington: National Academy os Science; 1961. p. 223-44.

22. Hallal PC, Victora CG. Reliability and validity of the international physical activity questionnaire (IPAQ). Med Sci Sports Exerc. 2004;36(3):556.

23. Robins JM, Greenland S. Identifiability and exchangeability for direct and indirect effects. Epidemiology (Cambridge, Mass). 1992;3(2):143-55.

24. Park MH, Sovio U, Viner RM, Hardy RJ, Kinra S. Overweight in childhood, adolescence and adulthood and cardiovascular risk in later life: pooled analysis of three british birth cohorts. PLoS One. 2013;8(7):e70684.

25. Buscot M-J, Magnussen CG, Thomson RJ, Viikari JSA, Juonala M, Raitakari OT, et al. Distinct child-to-adult body mass index trajectories are associated with different levels of adult cardiometabolic risk. Eur Heart J. 2018;39(24):2263-70.

26. Callo G, Gigante DP, Barros FC, Horta BL. Lifetime overweight and obesity and body composition in adulthood: the 1982 Pelotas (Brazil) birth cohort study. Cadernos de saude publica. 2016;32(4):e00174014.

27. Bastien M, Poirier P, Lemieux I, Després J-P. Overview of epidemiology and contribution of obesity to cardiovascular disease. Prog Cardiovasc Dis. 2014; 56(4):369-81.

28. Valentino G, Bustamante MJ, Orellana L, Kramer V, Duran S, Adasme M, et al. Body fat and its relationship with clustering of cardiovascular risk factors. Nutricion hospitalaria. 2015;31(5):2253-60.

29. Kuwahara K, Honda T, Nakagawa T, Yamamoto S, Hayashi T, Mizoue T. Body mass index trajectory patterns and changes in visceral fat and glucose metabolism before the onset of type 2 diabetes. Sci Rep. 2017:7:43521.

30. Simmonds M, Llewellyn A, Owen CG, Woolacott N. Predicting adult obesity from childhood obesity: a systematic review and meta-analysis. Obes Rev. 2016;17(2):95-107.

Ready to submit your research? Choose BMC and benefit from:

- fast, convenient online submission

- thorough peer review by experienced researchers in your field

- rapid publication on acceptance

- support for research data, including large and complex data types

- gold Open Access which fosters wider collaboration and increased citations

- maximum visibility for your research: over $100 \mathrm{M}$ website views per year

At $\mathrm{BMC}$, research is always in progress.

Learn more biomedcentral.com/submissions 